\title{
DIFERENÇA DE ALÍQUOTA E IMPOSTO SOBRE CIRCULAÇÃO DE MERCADORIAS E SERVIÇOS: SUBSTITUIÇÃO TRIBUTÁRIA
}

\section{ARTIGO ORIGINAL}

DEUS, Edgar Lucas de ${ }^{1}$

SILVA, Bruno Henrique dos Santos ${ }^{2}$

SANTOS, Igor Olímpio dos ${ }^{3}$

COSTA, Elaine Doro Mardegan 4

DEUS, Edgar Lucas de. Et al. Diferença de alíquota e imposto sobre circulação de mercadorias e serviços: Substituição Tributária. Revista Científica Multidisciplinar Núcleo do Conhecimento. Ano 05, Ed. 11, Vol. 10, pp. 129-145. Novembro de 2020. ISSN: 2448-0959, Link de

${ }^{1}$ Graduando em Ciências Contábeis - Fundação Educacional de Fernandópolis - FEF - Fernandópolis - SP.

2 Graduação em Administração: Habilitação em Marketing e Graduando em Ciências Contábeis - Fundação Educacional de Fernandópolis - FEF - Fernandópolis - SP.

${ }^{3}$ Graduando em Ciências Contábeis - Fundação Educacional de Fernandópolis - FEF - Fernandópolis - SP.

4 Orientadora. Bacharel em Ciências Contábeis (FACICA-Votuporanga, SP); Licenciatura Plena em Filosofia (CLARETIANO-Batatais, SP) e Pedagogia (FAEROlímpia, SP). Especialização em Economia Empresarial, Análise Financeira e Contábil (CEUV-Votuporanga, SP), Educação Inclusiva: uma perspectiva interdisciplinar (FIU-Pereira Barretos-SP) e Neuropedagogia Aplicada a Educação (FATECE-Pirassununga - SP). Mestre em Filosofia - área de concentração Ética (PUC-CAMPINAS), docente (FEF-Fernandópolis, SP), UNIFUNEC e Ensino Fundamental - Ciclo II (Santa Fé do Sul, SP). 
acesso:https://www.nucleodoconhecimento.com.br/contabilidade/mercadorias-eservicos

\section{RESUMO}

O imposto é tributo pago ao Estado para apoiar as despesas públicas. Esses pagamentos obrigatórios são exigidos tanto de pessoas físicas quanto jurídicas, sua arrecadação é o meio pelo qual o Estado possui, para financiar e obter recursos no desempenho de suas funções, ou seja, são fontes de renda, no qual a maioria da receita pública é obtida. Com arrecadação de impostos, o Estado obtém recursos suficientes para realizar suas ações, como: administração, infraestrutura ou prestação de serviços. Mediante tal importância o objetivo do presente trabalho aprofundar o conhecimento e identificar as melhorias do ICMS para mostrar as responsabilidades e a diferença entre o ICMS Diferencial de Alíquota (DIFAL) e o ICMS - substituição Tributária (ST). Realizou-se a pesquisa descritiva bibliográfica, sendo a coleta em material impresso e, em banco de dados eletrônicos, tornou-se possível discorrer sobre o conceito dos impostos, em específico, o conceito de ICMS, quais sujeitos são isentos desse imposto e como é realizado seu pagamento, como também sobre a ST e seu cálculo. Definiu- se o DIFAL, seu cálculo, bem como os fins e efeitos dos impostos, os seus elementos constituintes e os princípios que os regem. O que permitiu concluir que o ICMS, trata-se de um dos impostos mais importantes para o Brasil, pois contribui com os cofres públicos, sendo a maior fonte de renda fiscal do governo.

Palavras-chave: Impostos, ICMS, alíquota, DIFAL, ST.

\section{INTRODUÇÃO}

Os impostos são um dos instrumentos mais importantes com os quais o Estado conta para promover o desenvolvimento econômico, principalmente, porque é possível influenciar os níveis de alocação de renda entre população, seja por meio de certo nível de tributação entre os diferentes estratos ou, gastos sociais, que depende em grande parte do nível de captação de recursos alcançada (COELHO, 2017). 
O imposto tem a particularidade de não se basear em uma consideração específica ou direta por parte do reclamante. Seu objetivo é financiar as despesas do credor que, geralmente, é o Estado (BIAVA JÚNIOR; OYADOMARI, 2016).

Entre os elementos de um imposto, o evento tributável (a situação que motiva a obrigação tributária de acordo com a lei), o sujeito passivo (a pessoa, natural ou legal, que tem a obrigação de pagá-lo), a base tributável (a quantificação e avaliação do evento tributável), o tipo de imposto (a proporção a ser aplicada com base na base tributável para estabelecer o cálculo do imposto), a cota de impostos (o valor correspondente ao imposto) e a dívida tributária (o resultado da redução da taxa com deduções ou do aumento com sobretaxas) (BIAVA JÚNIOR; OYADOMARI, 2016).

Geralmente, os governos querem que os impostos sejam aplicados da maneira mais justa possível. Para conseguir isso, dois princípios fundamentais se aplicam: patrimônio horizontal e patrimônio vertical. O primeiro sustenta que os contribuintes com as mesmas características devem ser tratados da mesma maneira. $O$ segundo, princípio indica que pessoas que estão em circunstâncias diferentes devem ser tratadas de maneira diferente, conforme alguns critérios de justiça (FABRETTI, 2017).

Um dos impostos mais importantes para o Brasil é o (ICMS) Imposto sobre Circulação de Mercadorias e Serviços, que é instituído pelos Estados e Distrito Federal. Trata-se de um tributo estadual que incide sobre produtos de diferentes tipos, desde eletrodomésticos a chicletes, cuja aplicação é tanto para a comercialização dentro do país como fora do país, para bens importados. Na prática, este imposto é cobrado de forma indireta, ou seja, seu valor é adicionado ao preço do produto comercializado ou do serviço prestado (CASTRO et al., 2017).

O recolhimento do ICMS em empresas do Simples Nacional (SN) é realizado na própria guia do DAS (Documento de Arrecadação do Simples Nacional) que nessa guia 
consta os demais tributos. E, o (DIFAL) ICMS Diferencial de Alíquota só é recolhido em questão de compras interestaduais, com o recolhimento das diferenças das alíquotas (MARCHETTI, 2016).

Os impostos são pagos pelos sujeitos a quem as leis impõem as obrigações correspondentes. Esse fato não tem apenas um significado legal, uma vez que o pagamento do imposto impõe ao sujeito a necessidade de dispor dos valores líquidos para realizá-lo. O que, às vezes, implica também a necessidade de recorrer ao crédito em suas diversas formas. Tudo isso traz consequências para a conduta econômica do contribuinte e para as mudanças no mercado (BIAVA JÚNIOR; OYADOMARI, 2016).

Assim, volta-se o olhar deste trabalho para o objetivo de aprofundar o conhecimento e identificar as melhorias do ICMS para mostrar as responsabilidades e a diferença entre o ICMS Diferencial de Alíquota (DIFAL) e o ICMS - substituição Tributária (ST).

A metodologia proposta neste trabalho foi à pesquisa descritiva bibliográfica, sendo a coleta de dados realizada de março a setembro de 2020. Não houve determinação específica de tempo, porém foi dada maior relevância as publicadas recentes (últimos cinco anos), os descritores utilizados, na pesquisa foram: Impostos. ICMS. Alíquota. DIFAL. ST. Os descritores foram utilizados em diversas bases acadêmicas relacionando todos os termos. Após executadas as buscas com a combinação dos termos, os resumos dos artigos retornados pelos buscadores foram lidos e analisados.

Para realizar a coleta de dados, bem como a construção da base da Revisão da Literatura, seguiram-se os objetivos propostos, sendo realizados três capítulos, cuja sequência de ideias foi inicialmente, apresentar as noções fundamentais do ICMS; em seguida, verificar a relação de incidência, não incidência, fato gerador, base de cálculos, alíquotas e créditos; para finalizar mostrar as responsabilidades das empresas e a diferença entre o ICMS DIFAL e ST.

\section{OBJETIVOS}




\subsection{OBJETIVO GERAL}

Aprofundar o conhecimento e identificar as melhorias do ICMS para mostrar as responsabilidades e a diferença entre o ICMS Diferencial de Alíquota e o ICMS - ST.

\subsection{OBJETIVOS ESPECÍFICOS}

- Compreender as noções fundamentais do ICMS

- Verificar a relação de incidência, não incidência, fato gerador, base de cálculos, alíquotas e créditos.

- Mostrar responsabilidades das empresas e a diferença entre o ICMS Diferencial de Alíquota e o ICMS -

\section{REVISÃO DE LITERATURA}

\subsection{CONCEITOS GERAIS SOBRE IMPOSTOS}

Os impostos são uma parte substancial (ou melhor, a mais importante) da renda pública. Contudo, antes de definir os impostos, é necessário esclarecer a diferença entre os conceitos de renda pública, contribuição e imposto. Assim, em termos gerais Oliveira (2019) desta:

- A receita pública refere-se a todas as percepções do Estado, que podem ser em dinheiro ou em espécie ou serviços.

- Já a contribuição é parte integrante da receita pública e inclui contribuições de indivíduos, como pagamentos por serviços públicos, doações, multas

- Quanto à definição de imposto, devem-se observar vários elementos e, portanto, possui várias definições, mas o que se sabe é que são benefícios pecuniários, para o Estado e outras Entidades de direito público, que reivindicam na forma e quantidade determinadas

Em outras palavras, o imposto é parte proporcional da riqueza dos indivíduos deduzidos pela autoridade pública, a fim de fornecer essa parte das despesas gerais de utilidade pública que não cobrem receita de propriedade. Já que faz parte da receita 
nacional que o Estado se apropria de aplicá-lo à satisfação das necessidades públicas, distraindo-o das partes alíquotas dessa renda pertencentes às economias privados e sem oferecer compensação específica e recíproca da parte deles (FABRETTI, 2017).

Para Coelho (2017) imposto é (obrigação pecuniária em favor do credor fiscal) de direito público e se caracteriza por não exigir uma consideração direta ou determinada pela administração tributária (credor fiscal).

Os impostos, na maioria das legislações, surgem exclusivamente da "autoridade tributária do Estado", e tem como objetivo financiar as despesas. Seu princípio orientador, chamado "Capacidade Tributária", sugere que aqueles que têm mais devem contribuir mais para o financiamento estatal, para consagrar o princípio constitucional da equidade e o princípio social da liberdade (SABBAG, 2016).

Os impostos são encargos obrigatórios que indivíduos e empresas precisam pagar para financiar o Estado. Em resumo: sem impostos, o Estado não poderia funcionar, pois não teria

recursos para financiar a construção de infraestruturas (estradas, portos, aeroportos, eletricidade), prestar serviços públicos de saúde, educação, defesa, sistemas de proteção social (desemprego, benefícios por incapacidade ou acidentes de trabalho), etc. (FABRETTI, 2017).

A Lei nº 5.172/66, do Código Tributário Nacional (CNT), traz em seu bojo o conceito de tributos e sua regulamentação legal, como atividade pecuniária regulada pelo Estado (OLIVEIRA, 2018).

De acordo com Rousseau (2002, p. 14), o "Estado é constituído para organizar o contrato social pelo qual as pessoas abrem mão de parte dos seus interesses individuais para ser possível a vida social em harmonia". Nesse contexto, é evidente que o Estado necessita de recursos para cumprir suas funções, nessa premissa verifica-se sua legitimidade. 


\subsection{RELAÇÃO DE INCIDÊNCIAS ENTRE ICMS DIFAL E ST}

O ICMS é um imposto estadual e somente os Estados tem competência tributária para instituí-lo, conforme previsão constitucional. Ressalta-se ainda que, a Constituição somente autoriza que seja prevista como hipótese de incidência do ICMS, a circulação de mercadorias ou prestação dos serviços que especifica (serviços de transporte interestadual). Entre os vários impostos instituídos pela Constituição Federal de 1988 (CF/88), destaca-se o imposto sobre as operações relativas à circulação de mercadorias e sobre prestações de serviços (ICMS) (BRASIL, 2020).

Como já descrito o ICMS, trata-se de um dos principais tributos pagos ao Estado, o qual incide sobre todas as operações de venda de mercadorias e prestação de serviços de transporte e comunicação, legalmente previsto no art. 155 da CF. Este por sua vez, força as organizações a lidarem de forma assertiva com o seu recolhimento, o que não é nada fácil, pois o mesmo é de competência estadual e, encontra-se devidamente regulamentado. Porém ainda gera dúvidas entre os profissionais da contabilidade, administração entre outros, já que são muitos detalhes que demandam atenção especial, de forma a exigir atualização constante perante a legislação (PÊGAS, 2016).

As disposições legais também são encontradas na Lei Complementar ㄲo 87 de 1996, conhecida como Lei Kandir (BRASIL, 1996), salienta-se que a mesma vem sendo alterada pelas Leis Complementares 92/97, 99/99 e 102/2000, os legalmente, considerados como sujeitos isentos do ICMS: Transferência de propriedades ou bens móveis; Operações interestaduais relativas a transporte de petróleo e energia elétrica, quando destinados à industrialização ou à comercialização; Operações destinadas ao exterior (mercadorias, inclusive produtos primários e produtos industrializados semielaborados, ou serviços); Arrendamento mercantil; Alienação fiduciária; Operações com ouro (quando definido como ativo financeiro e instrumento cambial), atividades destinadas como prestação de serviço para uso do próprio autor; Operações com livros, jornais, periódicos e o papel destinado a sua impressão; Operações de que decorra a transferência de propriedade de estabelecimento comercial, industrial, ou de outra espécie (BRASIL, 2000). 
De acordo com a Resolução CFC $n^{\circ}$. 1.328/11 destaca que a realização do pagamento do ICMS, conforme as normas brasileiras ocorrem de três maneiras diferentes, sendo:

- DAS - Simples Nacional (Documento de Arrecadação do Simples Nacional): para as empresas optantes pelo Simples Nacional, o recolhimento do ICMS na guia mensal DAS - juntamente com o restante dos seus

- Guia própria estadual: a Secretaria Estadual da Fazenda de cada Estado disponibiliza uma guia própria para o recolhimento do tributo para as empresas optantes por outros regimes tributários.

- GNRE (Guia Nacional de Recolhimento Estadual): nos casos de operações interestaduais em que há diferença nas alíquotas do ICMS, é preciso efetuar o recolhimento por meio da

\subsection{PRINCIPAIS DIFERENÇAS ENCONTRADAS ENTRE O ICMS DIFAL E ST}

O regime de Substituição Tributária (ST) é uma forma de contribuição que está prevista na Constituição Federal de 1988, no Artigo 150, §7. Consiste, basicamente, na retenção antecipada do ICMS referente às operações subsequentes que existem no caminho dos produtos da fábrica até o consumidor final. Substituição tributária é o regime tributário no qual o pagamento do ICMS é de responsabilidade de uma única empresa. Essa empresa teria que pagar esse imposto em nome de todos os outros que fazem parte da cadeia de produção. A empresa compensará essa despesa inserindo o penhor no preço final do bem, por exemplo. (ÂMBITO JURÍDICO, 2013).

ST é atribuída a um contribuinte diferente daquele que realizou a ação de vendas. Como o próprio nome já diz, é uma maneira de substituir a pessoa responsável pelo pagamento dos impostos. De maneira simplificada, pode-se dizer que é a cobrança do imposto sobre vendas no momento da saída do setor, ou seja, em vez da cobrança feita quando a venda ocorre (fato que gera o imposto), é que será cobrado antecipadamente (MARIANO, 2017). 
Quando uma empresa decide solicitar a devolução do ICMS de uma venda feita para outro Estado, o fornecedor original do produto (ou seja, a empresa que paga o ICMSST em nome da cadeia produtiva) deve ser encontrado para fornecer documentação que comprova o pagamento do ICMS pelos produtos vendidos (JORNAL CONTÁBIL, 2020).

No caso de uma alteração na qualidade da mercadoria, deve-se ter em mente que você procura a orientação de um especialista, pois muitos empresários e gerentes acabam cometendo alguns erros tentando resolver esses problemas por conta própria e sem ajuda. A empresa poderá obter os documentos que comprovem a liquidação do ICMS, desde que incluía a empresa que efetuou a venda diretamente, sendo varejista, atacadista ou fabricante (OLIVEIRA, 2019).

A Substituição Tributária trata-se da retenção antecipada em operações posteriores. O ICMS-ST, como parte do valor de custo das mercadorias para fins de créditos de PIS e COFINS, é assunto que se discute, principalmente, em vista das soluções de consulta com resultados diferentes dentro da mesma estrutura (BIAVA JÚNIOR; OYADOMARI, 2016).

A Receita Federal cobra de cada um dos envolvidos, a percentagem correspondente a sua operação (venda ou transporte), frisa-se que nos casos de ST é a cobrança para o primeiro contribuinte envolvido em todo o processo, sendo assim este contribuinte passa a ser, portanto, o substituto tributário (MARIANO et al., 2017).

Frisa-se que o substituto é o responsável pela retenção e o repasse do tributo, concebido como fatos geradores, entretanto não arca com esta tributação. $O$ fato é que o ICMS incide sobre as operações, portanto todos os envolvidos no processo ainda pagam o ICMS (FERREIRA NETO; NICHELE, 2016).

De acordo com Mariano (2017) existem alguns detalhes que se bem observados e trabalhados facilitam o emprego do ICMS-ST, entre eles: deve integrar o preço final dos produtos, assim como qualquer outro imposto, se aplicável, o ICMS-ST deve fazer parte do preço de revenda do produto; não se aplica a todos os tipos de produtos ou 
serviços, a lista de itens é grande, mas não abrange todos os tipos de produtos ou serviços; portanto, procura entender se os produtos pertencem a esse grupo; as regras variam (de Estado para Estado), como o ICMS-ST possui competência do Estado, desde que realize transações interestaduais, pois se deve sempre verificar a incidência e os valores da ST.

O entendimento dessa mecânica pode trazer benefícios para a sua empresa de uma maneira simples, em alguns casos, o imposto pago na aquisição das mercadorias pode ser reduzido a partir das saídas (PAULSEN, 2017).

Na visão de Marchett (2018), não é nada fácil calcular a substituição tributária, sendo necessário o conhecimento de alguns itens, como: Estado de origem; Estado de destino; Produto NCM (Nomenclatura Comum do Mercosul); Tipo de estabelecimento (atacado, indústria ou varejo); Regime tributário (simples, real ou presumido), Destino da mercadoria (comercialização, industrialização ou consumidor final), Valores da mercadoria, frete e outros itens, como IPI, desconto etc.; MVA - Margem de Valor Agregado.

Enfim, nota-se que não se trata de um cálculo trivial, assim, propõe-se a compreensão a partir de alguns exemplos descritos por ST Coad (2020):

Quadro 1: Exemplificando o cálculo estadual 


\section{CÁLCULO ESTADUAL}

Para calcular o ICMS ST, em uma operação dentro do estado, deve-se verificar qual é o MNA (Margem de Valor Agregado) indicado para o produto da operação.

Ao considerar um MVA de $35 \%$ para o cálculo, tem-se o seguinte resultado:

No cálculo, pondera-se como exemplo a compra de um produto cuja nota fiscal tenha as seguintes caracteristicas:

Total de produtos: $1.000,00$

IPI total: 100,00

Total de ICMS em destaque: 120,00

Total da nota (produtos + IPI): $1.100,00$

O cálculo do ICMS ST tem como base o total da fatura, que se deve incluir o IPI sempre que existir. Portanto, ao usar o MNA fornecido aqui como exemplo, será aplicado ao total da fatura e adicionado a esse.

Cálculo da base de cálculo do ICMS ST

Fatura total da fatura $\times$ MVA: $1.100,00 \times 35 \%=385,00$

Base de cálculo do ICMS ST: $1.100,00+385,00=1.485,00$

Após localizar a base de cálculo do ICMS ST, a aliquota a tual de ICMS para este produto no Estado deve ser aplicada e o ICMS em destaque na fatura deve ser deduzido. Por exemplo, considera-se a porcentagem padrão de $18 \%$

Base de cálculo do ICMS ST $x$ aliquota: $1.485,00 \times 18 \%=267,30$

ICMS ST: $267,30-$ ICMS em destaque $=267,30-120,00=147,30$

Ao concluir o cálculo, será possivel verificar que o ICMS ST a ser cobrado para esta nota fiscal será de R S 147,30 .

Fonte: ST COAD, 2020, não paginado.

Quadro 2: Exemplificando o cálculo interestadual 


\section{CÁL CUL O INTE REST ADUAL}

Para o cálculo interestadual, devem-se avaliar os seguintes dados da fatura:

Valor total da mercadoria - R $\$ 10.000,00$

Valor total do IPI - R $\$ 700,00$

Aliquota Interestadval - $12 \%$

ICMS Mesmo da operação - R S 1200,00

IVA da operação $-45 \%$

Primeiro, deve-se calcular a base de cálculo da Substituição Tributária do ICMS.

Adiciona-se o valor total dos produtos e o valor do IPI, com essa soma, denominase como valor total. Em seguida, usa-se o Valor Total e multiplica-se pelo IVA da operação. Com esse resultado, adiciona-se ao val or total para que o val or da base de cálculo do ICMS ST seja calculado.

Por exemplo:

$$
\begin{aligned}
& 10.000+700=\text { Valor total } 10.700 \\
& 10.700 \times 45 \%=4.815 \\
& 10.700+4.815=15.515-\text { Base de call culo do ICMS } s T
\end{aligned}
$$

Após cal cular o valor da base de cálculo do ICMS ST, multiplica-se esse valor pela aliquota interna do produto. No modelo de cálculo, considera-se $18 \%$, mas para cada produto, é necessário fazer consultas para confimar as informações.

\section{$15.515 \times 18 \%=2.792,70$ Substi tvição do ICMS sobre ICMS}

Esse seria o valor a ser cobrado em relação à substituição tributária. Entretanto, nesse caso, tem-se o ICMS da própria operação que foi coletada. Com isso, desconta-se o valor total do ICMS S T.

$$
2792,70-1200=1592,70 \text { Valor a ser coletado ref. ST }
$$

O valor a ser recolhido nessa operação interestadual com incidência de substitui g̃o tributária é de R S $1.592,70$.

Fonte: ST COAD, 2020, não paginado.

Tendo em vista que o ICMS é um imposto de competência estadual, a aplicação da ST envolve diversas questões a serem consideradas. Dentre vários fatores importantes, encontra- se a compreensão clara sobre o funcionamento do processo econômico com mercadorias, pois se torna peça chave neste sistema, já que, é possível identificar o método de arrecadação mais adequado para cada tipo de situação (COUTINHO, 2020). 
Como forma de distinção, é preciso salientar que anteriormente a aplicação do ST, o ICMS era taxado em cada operação do processo, ou seja, era feito de forma regular e individual para cada contribuinte que fazia o seu repasse a Receita, ocasionalmente era gerado um altíssimo número de notas que passavam pela análise fiscal, sujeita a diversos erros, portanto é possível afirmar que a ST foi criada para simplificar o processo, tornando o mais ágil e fácil para o Governo (CARRAZZA, 2017).

Cabe discorrer sobre o DIFAL (Diferenciação de Alíquota do ICMS), este na verdade trata-se de uma ferramenta concebida pela Emenda Constitucional 87/15 e pelo Convênio ICMS 93/15, os quais alteram a forma de cálculo e recolhimento do tributo nas relações interestaduais (BRASIL, 2015).

Acredita-se que o mesmo foi criado com a finalidade de tornar mais justa as operações interestaduais, vez que estas possuem valores diferentes de uma UF outra, é particularmente importante considerar as diferenças encontradas no momento do recolhimento, por exemplo, no Estado de origem a alíquota corresponde a $12 \%$, entretanto no Estado destinatário a mesma é de 17\%, faz-se necessário calcular o DIFAL em 5\% sobre o valor total da operação (COUTINHO, 2020).

No Brasil trava-se a chamada Guerra Fiscal, os Estados reduzem suas alíquotas do ICMS com o fim de atrair os comerciantes e consecutivamente aumentam suas arrecadações, outro motivo que fundamentou a criação do DIFAL, a equalização deste cenário, bem como a garantia da competitividade entre os Estados (JORNAL CONTÁBIL, 2020).

De acordo com o Jornal Contábil (2020), após apurar a base de cálculo do ICMS, é preciso calcular o FCP, o valor do DIFAL e, por fim, efetuar a partilha do montante, em relação a essa última conta, todo o valor será para o Estado destinatário da mercadoria.

Quadro 3: Exemplo de como calcular o valor do DIFAL. 
Imagine um exemplo cuja base de cálculo de uma mercadoria é de $R S 2.000,00$, já que a mesma será enviada de SP para RJ. Para chegar ao FCP, us a-se a conta:

$$
\begin{aligned}
& \mathrm{FCP}=\text { base do } \mathrm{ICMS} *(\% \text { do } \mathrm{FCP} / 100) \\
& \mathrm{FCP}=2.000 *(2 \% / 100) \\
& \mathrm{FCP}=2.000 * 0,02 \\
& \mathrm{FCP}=40 .
\end{aligned}
$$

Para calcular o DIFAL, realiza-se a equação:

DIFAL = base do ICMS * (aliquota ICMS intra - aliquota ICMS inter $) / 100$ ),

$$
\begin{aligned}
& \text { DIF AL }=2.000 *(18 \%-12 \%) / 100 ; \\
& \text { DIF AL }=2.000 *(6 \% / 100) \\
& \text { DIF AL }=2.000 * 0.06 ; \\
& \text { DIF AL }=120 .
\end{aligned}
$$

Por fim, como todo o montante será para o estado de des tino, basta somar o DIFAL (RS 120) a FCP (RS 40), o que resulta em RS 160 para ser enviado.

Fonte: Jornal Contábil, 2020, não paginado.

Será a empresa a responsável para efetuar o recolhimento correto do DIFAL. Entretanto, não basta que a organização simplesmente saiba fazer os cálculos, há outras adaptações necessárias a serem feitas nos processos contábeis e tributários para que não haja prejuízo ao negócio (SABBAG, 2016).

De acordo com Coutinho (2020), dentre os elementos fiscais a serem considerados encontra-se, o evento tributável, circunstância cuja realização, de acordo com a lei, origina a obrigação tributária. O sujeito passivo: quem deve, é a pessoa singular ou coletiva obrigada por lei a cumprir os benefícios fiscais. O Assunto ativo, cuja entidade administrativa é diretamente beneficiada pela cobrança do imposto, que faz com que a receita do respectivo imposto apareça em seu orçamento. A Base tributável, a quantificação e avaliação do evento tributável e determina a obrigação tributária.

A Taxa de imposto, cuja proporção é aplicada à base tributável para calcular o imposto, essa proporção pode ser fixa ou variável. E por fim a Dívida tributária, 
resultado após a redução da cota com possíveis deduções e aumento com possíveis sobretaxas, que devem ser pagas.

\section{CONSIDERAÇÕES FINAIS}

Assim, o presente estudo teve como foco o ICMS, cujas operações interestaduais entre as mercadorias que tem recolhimento diferente, o ICMS - DIFAL e também o ICMS - ST, pois estes em seus cálculos precisam observar os vários fatores, origens, destinos, produtos e também o enquadramento da empresa.

Sobre o DIFAL, de acordo com Brasil (2015) e Coutinho (2020), trata-se de uma diferença entre as alíquotas dos estados, que surge quando há uma compra ou venda entre Estados, no qual cada Estado tem sua alíquota interna e entre as (compras ou vendas) entre Estados tem sua alíquota interestadual. Com isso o comprador da mercadoria, deverá pagar a diferença da alíquota interestadual e a alíquota interna do seu Estado e essa diferença de imposto fica para o Estado onde os compradores estão localizados.

Já a ST, de acordo com Mariano (2017), se refere ao tipo de ICMS, no qual a responsabilidade do citado imposto fica atribuída ao contribuinte diferente que realizou a venda. Para simplificar, pode-se dizer que o ICMS-ST é sobre a venda do produto, sendo recolhido antecipadamente no momento que sai do remetente da mercadoria, diferente do ICMS DIFAL que o recolhimento é realizado após, quando a mercadoria já chegou ao seu destino.

Assim conclui-se que o DIFAL, não se estabelece como um novo tipo de imposto que por sua vez, trata-se apenas de um instrumento utilizado para encontrar o equilíbrio da arrecadação de impostos entre os Estados brasileiros, pois se tornou fundamental para estabelecer uma justiça tributária sendo obrigatório a todas as empresas que realizam vendas interestaduais.

Ao partir dos pressupostos apresentados, constatou-se que essa discussão torna-se extremamente necessária para auxiliar as organizações em casos de mudanças nas resoluções em Cálculos de ICMS. 


\section{REFERÊNCIAS BIBLIOGRÁFICA}

ÂMBITO JURÍDICO. O mecanismo da substituição tributária no ICMS e seus aspectos jurídicos, econômicos e constitucionais. 2013. Disponível em:

<https://ambitojuridico. com.br/cadernos/direito-tributario/omecanismo-da-substituicao-tributaria-no-icms-e-seusaspectos-juridicoseconomicos-e-constitucionais/>. Acesso em: 20 maio 2020.

BIAVA JÚNIOR, R.; OYADOMARI, J.C.T. Impactos da substituição tributária do ICMS na lucratividade e nos custos empresariais. Revista de Contabilidade da UFBA, Salvador, v. 71-91, mai./ago. 2016. Disponível em $<$ https://portalseer.ufba.br/index.php/rcontabilidade

/article/view/4456>. Acesso em: 20 maio 2020.BRASIL. Constituição da República Federativa do Brasil de 1988. Disponível em: <http:// www.planalto.gov.br/ccivil_03/constituicao/constituicao.htm>. Acesso em: 20 maio 2020.

Lei Complementar no 87, de 13 de setembro de 1996. Disponível em<http://www.fazenda.df.gov.br/aplicacoes/legislacao/legislacao/TelaSaidaDocume nto.cfm?txtNumero=87\&txtAno=1996\&txtTipo=190\&txtParte=.\#: :text=LEI\%20COMP LEMENTAR\%20N\%C2\%BA\%2087\%2C\%20DE,comunica\%C3\%A7\%C3\%A30\%2C \%20 \%20d\%C3\%A1\%20outras\%20provid\%C3\%AAncias>. Acesso em: 20 maio 2020.

ICMS: aspectos gerais. 2000. Disponível em:http://www.portaltributario.com.br//icms.html. Acesso em: 26 maio 2020.

Convênio ICMS 93, de 17 de setembro de 2015. Disponível em: https://www.confaz. fazenda.gov.br/legislacao/convenios/2015/CV093_15. Acesso em: 26 maio 2020. 
. Competências tributárias estão na Constituição. 2020. Disponível em: $<$ https:// www12.senado.leg.br/emdiscussao/edicoes/pacto-federativo/partilha-dostributos/ competencias-tributarias-estao-na-constituicao>. Acesso em: 20 maio 2020.

CAMARGO, R.F. ICMS e tudo que você precisa saber sobre ele: alíquota, cálculo e contribuintes do Imposto sobre Circulação de Mercadorias e Serviços. 2017. Disponível em:

$<$ https://www.treasy.com.br/blog/icms-imposto-sobre-circulacao-de-mercadorias-eservicos/.>. Acesso em: 26 maio 2020.

CARRAZZA, R. A. Curso de direito constitucional tributário. 27. ed. São Paulo: Malheiro Editores, 2017.

CASTRO, F.A.V. et al. Gestão e planejamento de tributos. Rio de Janeiro: FGV, 2017.

CFC. Conselho Federal de Contabilidade de 1946. Disponível em: $<$ https://cfc.org.br/tecnica/normas-brasileiras-de-contabilidade/>. Acesso em: 20 maio 2020.

COELHO, F. U. Manual de direito comercial: direito de empresa. 18. ed. São Paulo: Saraiva, 2017.

COUTINHO, L. Vantagens e desvantagens da substituição tributária e da antecipação tributária do ICMS no Estado de São Paulo: análise de um modelo ideal. 2020.

Disponível

em:<https://www.univem.edu.br/anaiscpc2012/pdf/Artigos\%20-

\%20Vantagens\%20e\%20 desvantagens\%20da\%20Substituicao\%20Tributaria.pdf >. Acesso em: 03 abr. 2020.

FABRETTI, L. C. Contabilidade tributária. 16. ed. São Paulo: Atlas, 2017.

FERREIRA NETO, A.M.; NICHELE, R. (Coord.) Curso avançado de substituição tributária: modalidades e direitos do contribuinte. São Paulo: IOB, 2016. 
JORNAL CONTÁBIL. ICMS: entendo o conceito da Substituição Tributária (ST). Disponível em: <https://www.jornalcontabil.com.br/icms-st-tudo-sobre-a-substituicaotributaria-do-icms/>. Acesso em: 16 abr. 2020.

MARIANO, P. A.; WERNECK, R.; BEZERRA, S.R.A. Substituição tributária no ICMS: aspectos jurídicos e práticos. 11. ed. São Paulo: IOB, 2017.

MARCHETTI, L.Z. O impacto do ICMS substituição tributária em uma indústria optante pelo simples nacional. 2018. 94 f. Tese de Graduação. Universidade Federal Fluminense, Volta Redonda/RJ. Disponível em: $<$ https://app.uff.br/riuff/bitstream/1/7508/1

/Larissa\%20Zen\%C3\%B3bio\%20Marchetti.pdf> Acesso em: 20 maio 2020.

PAULSEN, L. Responsabilidade e substituição tributárias. 2017. 268 f. Tese (Doutorado em Direitos e Garantias do Contribuinte) - Universidade de Salamanca, Espanha, $2017 . \quad$ Disponível em: https://books.google.com.br/books/about/Responsabilidade_e_Substitui\% C3\%A7\%C3\%A30_Tribut.html?id=zZRRDwAAQBAJ\&printsec=frontcover\&source=k p_rea d_button\&redir_esc=y\#v=onepage\&q\&f=false. Acesso em: 20 de maio de 2020 .

OLIVEIRA, G. P. Contabilidade tributária. 13. ed. São Paulo: Saraiva, 2019.

OLIVEIRA, L. M. et al. Manual de contabilidade tributária. 19. ed. São Paulo: Atlas, 2018.

PÊGAS, P. H. Manual de contabilidade tributária. 10. ed. Rio de Janeiro: Freitas Bastos, 2016.

ROSA, J.R. Substituição tributária no ICMS: manual explicativo. 12. ed. Itu: Ottoni Editora, 2017.

ROUSSEAU, J.J. Do contrato social. São Paulo: Martin Claret, 2002.

SABBAG, E. Manual de direito tributário. 3. ed. São Paulo: Saraiva, 2016. 
ST COAD. Substituição tributária: cálculo do ICMS a ser retido. 2020. Disponível em:

$<$ https://www.substituicaotributaria.com/SST/substituicao-tributaria/regra-

geral/?id=13>. Acesso em: 20 maio 2020.

Substituição tributária: cálculo do DIFAL. 2020. Disponível em: <https://www. substituicaotributaria.com/SST/substituicao-tributaria/regra-geral/?id=707>. Acesso em: 20 maio 2020.

Enviado: Outubro, 2020.

Aprovado: Novembro, 2020. 